Article

\title{
Improvement of DC Fault Current Limiting and Interrupting Operation of Hybrid DC Circuit Breaker Using Double Quench
}

\author{
Sang-Jae Choi ${ }^{1}$, Jun-Hyup Lee ${ }^{2}{ }^{(0}$, Jin-Wook Lee ${ }^{3}\left[\right.$ and Sung-Hun Lim ${ }^{1, *(1)}$ \\ 1 Department of Electrical Engineering, Soongsil University, 369 Sangdo-ro, Dongjak-gu, Seoul 156-743, Korea; \\ choisj203@soongsil.ac.kr \\ 2 Department of Chemical Engineering, Soongsil University, 369 Sangdo-ro, Dongjak-gu, Seoul 156-743, Korea; \\ unhyuplee@ssu.ac.kr \\ 3 Department of Mechanical Engineering, Soongsil University, 369 Sangdo-ro, Dongjak-gu, \\ Seoul 156-743, Korea; immanuel@ssu.ac.kr \\ * Correspondence: superlsh73@ssu.ac.kr; Tel.: +82-2-828-7268
}

Citation: Choi, S.-J.; Lee, J.-H.; Lee, J.-W.; Lim, S.-H. Improvement of DC Fault Current Limiting and Interrupting Operation of Hybrid DC Circuit Breaker Using Double Quench. Energies 2021, 14, 4157. https://doi.org/10.3390/en14144157

Academic Editors: Teuvo Suntio and Hyosung Kim

Received: 28 April 2021

Accepted: 15 June 2021

Published: 9 July 2021

Publisher's Note: MDPI stays neutral with regard to jurisdictional claims in published maps and institutional affiliations.

Copyright: (c) 2021 by the authors. Licensee MDPI, Basel, Switzerland. This article is an open access article distributed under the terms and conditions of the Creative Commons Attribution (CC BY) license (https:// creativecommons.org/licenses/by/ $4.0 /)$.

\begin{abstract}
In this paper, direct current (DC) fault current limiting and interrupting operation of hybrid DC circuit breaker (DCCB) using double quench, which consists of DCCB, a series resonance circuit, power electronic switch, surge arrestor, two separated current limiting reactor/resistor, and two superconducting elements, were suggested. The suggested hybrid DCCB can perform the interrupting operation after twice or once DC fault current limiting operation according to DC fault current amplitude. To verify the effective operation of the suggested hybrid DCCB, the modeling for the components of DCCB, the surge arrestor, and the SCE was carried out and its DC operational characteristics were analyzed. Through the analysis of the modeling results for the suggested hybrid DCCB, the advantages of hybrid DCCB were discussed.
\end{abstract}

Keywords: hybrid DC circuit breaker (DCCB); double quench; superconducting elements; DC fault current limiting and interrupting operation

\section{Introduction}

Recently, direct current (DC) grid, called as low voltage DC (LVDC), medium voltage DC (MVDC), or high voltage DC (HVDC) system, has been receiving attention due to the increase of DC load and DC distributed power source and thus the various protection devices for DC grid such as DC circuit breaker (DCCB) have been developed. One of the important technologies in DCCBs is that the increased DC current is to make rapid zero crossings. Another one is to effectively remove the arc in mechanic contact comprising the DCCB. To achieve these technologies in DCCB, the hybrid DCCBs or the modified DCCBs, which utilize the power electronic switches with higher ratings, have been introduced continuously [1-5].

Moreover, the DCCBs, which can achieve the fault current limiting operation shortly before the fault current interruption, have been suggested and the improvement of the DCCB's performance through the combination of the superconducting elements (SCEs) has been constantly reported [6-10].

In this paper, the hybrid DCCB using double quench of SCEs, which has a mechanical switch (MS), power electronic switch (PS), two SCEs, and two separated current limiting reactor/resistor (CLRs), were proposed and the effect of twice DC fault current limiting operations according to the amplitude of DC fault current on the interrupting operation of the DCCB was analyzed through the PSCAD/EMTDC (power system computer-aided design/electro-magnetic transient including direct current) simulation.

With the PSCAD/EMTDC modeling for the mathematical characteristic equation of each component, the double quench generation of the SCEs comprising the hybrid DCCB was confirmed to be contributed to the successful DC fault current interruption along with 
twice DC fault current limiting operation through the comparative analysis with the case of the hybrid DCCB without two SCEs and two separated CLRs.

\section{Structure and Modeling of Hybrid Direct Current Circuit Breaker (DCCB) Using Double Quench}

\subsection{Structure of Hybrid Direct Current Circuit Breaker (DCCB) Using Double Quench}

The structure of the hybrid DCCB using double quench consists of two CLRs and two SCEs as DC current limiting components, MS, LC series circuit and PS as DC current interrupting components, and surge arrestor (SA) as overvoltage prevention as shown in Figure 1. The series resonance circuit has a parallel connection with MS to induce zero current crossings in MS in case of the DC fault current occurrence. PS, connected in series the controller. The $\mathrm{SCE}_{1}$ acts as both the fault detector and the initial DC fault current limiter. The quench occurrence in $\mathrm{SCE}_{1}$ directly after the fault happens makes the $\mathrm{CLR}_{1}$ act as the first fault current limiter through $\mathrm{SCE}_{2}$. In case that the larger DC fault current flows into $\mathrm{SCE}_{2}$ despite the quench occurrence of the $\mathrm{SCE}_{1}$, the quench in $\mathrm{SCE}_{2}$ occurs sequentially and the second DC fault current limiting operation of the hybrid DCCB can be achieved. After the $\mathrm{DC}$ fault current limiting operation through single quench in $\mathrm{SCE}_{1}$ or double quench in both $\mathrm{SCE}_{1}$ and $\mathrm{SCE}_{2}$ comprising the hybrid DCCB according to the amplitude of the DC fault current, the DC fault current interrupting operation through the MS is achieved by its opening operation and then, finally separated from the DC fault current path by the opening of PS. The SA pre-vents the over-voltage across the DCCB during the DC current limiting and the interrupting operation.

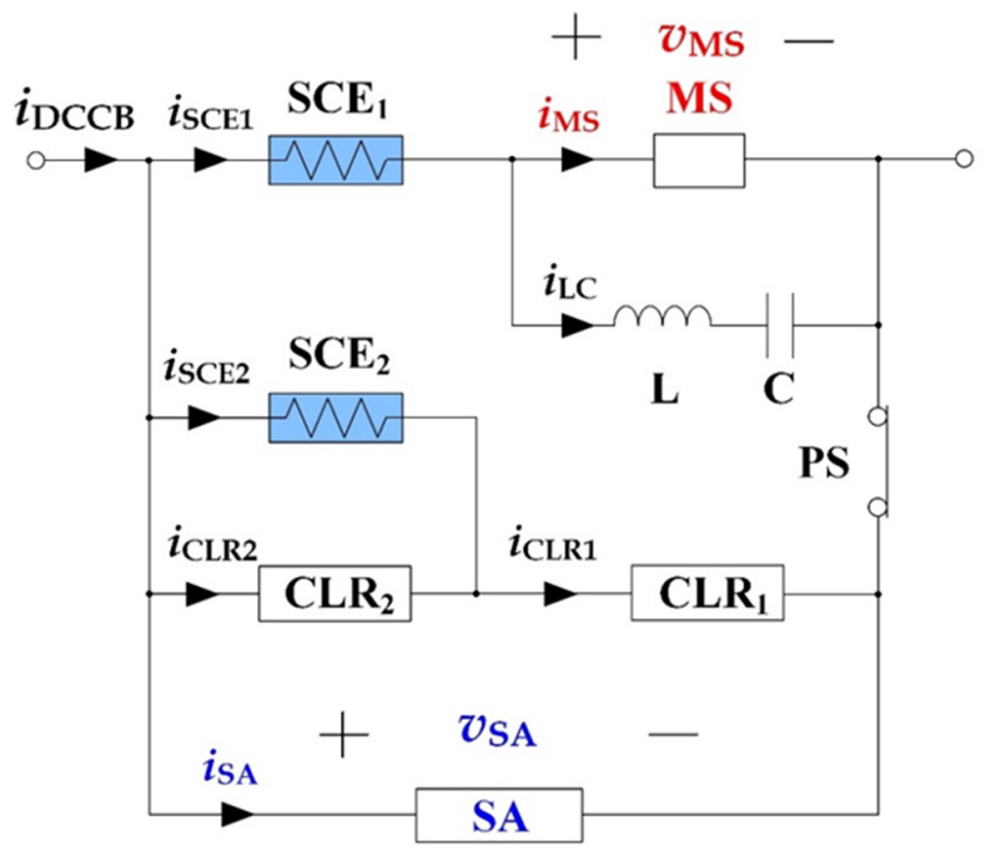

Figure 1. Structure of hybrid Direct Current (DC) circuit breaker using double quench; SCE: superconducting element; MS: mechanical switch; CLR: current limiting resistor/reactor; SA: surge arrestor; PS: power switch.

\subsection{Modeling of Hybrid Direct Current Circuit Breaker (DCCB) Using Double Quench}

To analyze the current limiting and the interrupting characteristics, the PSCAD/EMTDC modeling for the suggested hybrid DCCB using a double quench of two SCEs was carried out. MS, SCE, and SA were considered as the main modeling components.

For the MS's dynamic arc behavior, the arc conductance (GMS) was reflected into the PSCAD/EMTDC modeling from Mayr's arc model as expressed in Equation (1) and modeled to generate directly after the MS current $\left(i_{\mathrm{MS}}\right)$ exceeded $8 \mathrm{kA}$. In Equation (1), $G_{0}$, $Q_{0}$, and $\tau_{\mathrm{a}}$ represent the conductance of insulation material between two conducting plates, 
the heat energy, and the time constant of arc, respectively [11,12]. The resistance of each SCE, which generates in case that the current in SCM $\left(i_{\mathrm{SCM} 1}, i_{\mathrm{SCM} 2}\right)$ exceeds the critical current $\left(I_{\mathrm{C} 1}, I_{\mathrm{C} 2}\right)$, was reflected into its PSCAD/EMTDC modeling with the resistance equation, represented in Equation (2). $R_{\mathrm{N}}$ and $\tau_{\mathrm{b}}$ in Equation (2) express the normal resistance and time constant of SCE, respectively $[13,14]$.

In addition, the PSCAD/EMTDC modeling for the SA was considered with the resistance of Equation (3) derived from its voltage and current relation with the breakdown voltage $\left(V_{\mathrm{B}}\right)$ and the nonlinear index $(\gamma)$ [15]. The current in the MS (i $\left.i_{\mathrm{MS}}\right)$ directly after the DC fault occurrence can be obtained as Equation (5) from the second differential equation for the current of the MS ( $\left.i_{\mathrm{MS}}\right)$ as shown in Equation (4). In Equations (5) and (6), $n$ and $k$ represent the cycle number of the zero current point in the current of MS and the ratio of the voltage variation induced in the MS $\left(\Delta v_{\mathrm{MS}}\right)$ over the current variation of MS $\left(\Delta i_{\mathrm{MS}}\right)$, respectively.

$$
\begin{gathered}
G_{\mathrm{MS}}(t)=G_{0} \times \exp \left(\int_{\mathrm{t}_{1}}^{\mathrm{t}} \frac{v_{\mathrm{MS}}(\lambda) i_{\mathrm{MS}}(\lambda)}{Q_{0}} d \lambda\right) \times \exp \left(-\frac{t}{\tau_{a}}\right) \\
R_{\mathrm{SCE}}(t)=R_{\mathrm{N}} \times \sqrt{1-\exp \left(-\frac{t}{\tau_{\mathrm{b}}}\right)} \\
R_{\mathrm{SA}}(t)=V_{\mathrm{B}} \gamma_{v_{\mathrm{SA}}}(t)^{1-\gamma} \\
\frac{d^{2} i_{\mathrm{MS}}(t)}{d t^{2}}+\frac{k}{L} \frac{d i_{\mathrm{MS}}(t)}{d t}+\frac{1}{L C} i_{\mathrm{MS}}(t)=\frac{1}{L C} I_{\mathrm{CB}} \\
i_{\mathrm{MS}}(t)=I_{\mathrm{CB}}\left[1-\frac{e^{-\alpha \frac{2 n-1}{2} \pi}}{\sin \beta \frac{2 n-1}{2} \pi} e^{\alpha t} \sin \beta t\right] \\
\alpha=-\frac{k}{2 L} \quad \beta=\sqrt{\frac{1}{L C}-\left(\frac{k}{2 L}\right)^{2}}
\end{gathered}
$$

To verify the merits of the suggested hybrid DCCB using double quench, the simulated DC system was constructed as shown in Figure 2. The specifications for the simulated DC system were listed in Table 1. For DC short-circuit simulation with different amplitude of DC fault current, $\mathrm{SW}_{21}$ or $\mathrm{SW}_{22}$ was closed individually for $0.01 \mathrm{~s}$ for larger DC fault current and lower $\mathrm{DC}$ fault current after $\mathrm{SW}_{1}$ was closed. The values of the parameters, described in the modeling of MS, $\mathrm{SCE}_{1}, \mathrm{SCE}_{2}$, and $\mathrm{SA}$ comprising the hybrid $\mathrm{DCCB}$, were listed in Table 2 together with $\mathrm{CLR}_{1}, \mathrm{CLR}_{2}$, and series resonance circuit.

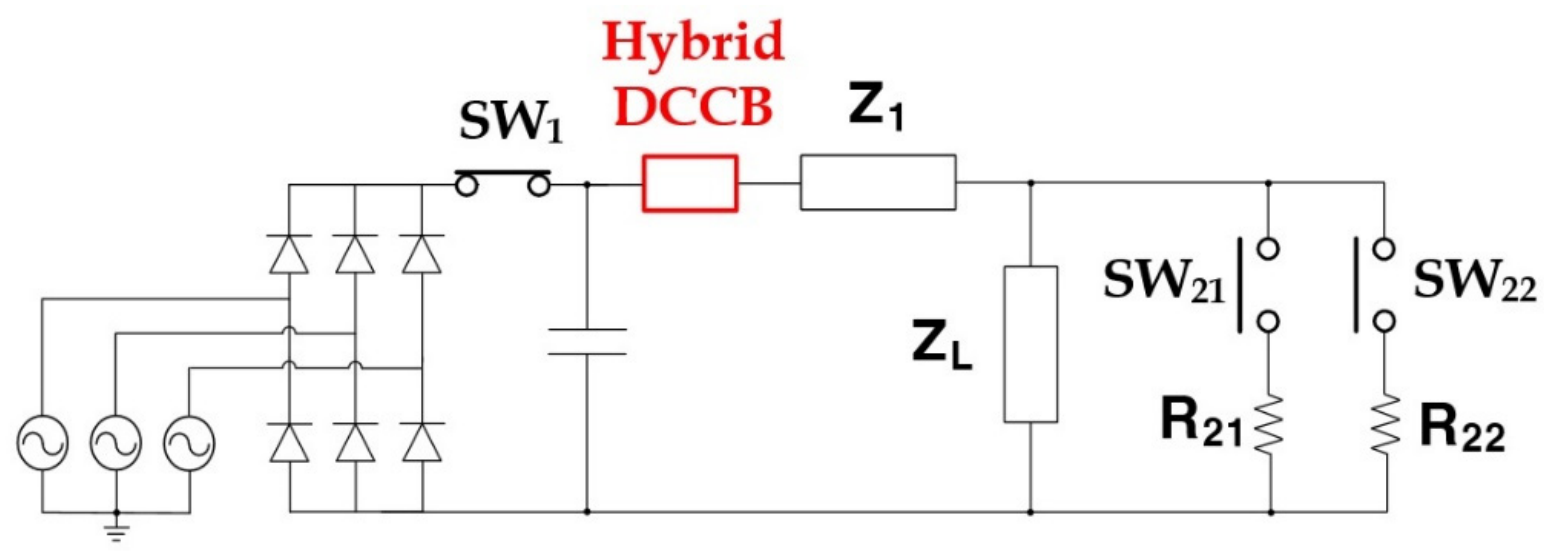

Figure 2. Simulated DC system for the operation of hybrid DCCB using double quench; $Z_{1}$ : line impedance; $Z_{L}$ : load impedance; $\mathrm{R}_{21}$ : small DC fault resistance; $\mathrm{R}_{22}$ : large $\mathrm{DC}$ fault resistance. 
Table 1. Specification of DC System for DC Short-Circuit Tests.

\begin{tabular}{cccc}
\hline DC System Circuit & Parameters & Value & Unit \\
\hline DC source voltage & $\mathrm{V}_{\mathrm{DC}}$ & 15 & $\mathrm{kV}$ \\
\hline Line impedance $\left(\mathrm{Z}_{1}\right)$ & $\mathrm{R}_{1}$ & 0.01 & $\Omega$ \\
& $\mathrm{X}_{1}$ & 0.377 & $\Omega$ \\
\hline Load impedance $\left(\mathrm{Z}_{\mathrm{L}}\right)$ & $\mathrm{R}_{\mathrm{L}}$ & 0.6 & $\Omega$ \\
\hline Small DC Fault Resistance & $\mathrm{R}_{21}$ & 0.6 & $\Omega$ \\
\hline Large DC Fault Resistance & $\mathrm{R}_{22}$ & 1.2 & $\Omega$ \\
\hline
\end{tabular}

Table 2. Design Parameters of Components Comprising Hybrid DCCB using Double Quench.

\begin{tabular}{|c|c|c|c|c|}
\hline Components & Description & Parameters & Value & Unit \\
\hline \multirow{3}{*}{ MS } & $\begin{array}{c}\text { Conductance of insulation } \\
\text { material }\end{array}$ & $G_{0}$ & $5.5 \times 10^{15}$ & - \\
\hline & Heat energy & $Q_{0}$ & 15 & - \\
\hline & Time constant of arc & $\tau_{\mathrm{a}}$ & 1 & - \\
\hline \multirow{2}{*}{$\begin{array}{c}\text { Series Resonance } \\
\text { Circuit }\end{array}$} & Series inductance & $L$ & 87 & $\mu \mathrm{H}$ \\
\hline & Series capacitance & C & 3.33 & $\mu \mathrm{F}$ \\
\hline \multirow[t]{2}{*}{$\mathrm{SCE}_{1}$} & Normal resistance of $\mathrm{SCE}_{1}$ & $R_{\mathrm{N} 1}$ & 1 & $\Omega$ \\
\hline & Normal resistance of $\mathrm{SCE}_{2}$ & $R_{\mathrm{N} 2}$ & 20 & $\Omega$ \\
\hline \multirow[t]{3}{*}{$\mathrm{SCE}_{2}$} & Time constant of $\mathrm{SCE}_{1} \& \mathrm{SCE}_{2}$ & $\tau_{\mathrm{b}}$ & 0.1 & - \\
\hline & Critical current of $\mathrm{SCE}_{1}$ & $I_{\mathrm{C} 1}$ & 5 & $\mathrm{kA}$ \\
\hline & Critical current of $\mathrm{SCE}_{2}$ & $I_{\mathrm{C} 2}$ & 7 & $\mathrm{kA}$ \\
\hline $\mathrm{CLR}_{1}$ & Current limiting reactance & $\mathrm{L}_{\mathrm{CLR}}$ & 2 & $\mathrm{mH}$ \\
\hline $\mathrm{CLR}_{2}$ & Current limiting resistance & $\mathrm{R}_{\mathrm{CLR}}$ & 2 & $\Omega$ \\
\hline \multirow{2}{*}{ SA } & breakdown voltage & $V_{\mathrm{B}}$ & 20 & \multirow{2}{*}{$\mathrm{kV}$} \\
\hline & nonlinear index & $\gamma$ & 8 & \\
\hline
\end{tabular}

\section{Results and Discussion}

The improvement of the DC current limiting and interrupting operations of the suggested hybrid DCCB was analyzed from the simulation results for the larger DC fault current and the lower DC fault current situations.

Figure 3 shows the DC fault current limiting and interrupting operation of the suggested hybrid DCCB in case of the larger DC fault current occurrence. With the arc conductance in Equation (1) calculated using the voltage and the current of the MS, the voltage $\left(v_{\mathrm{MS}}\right)$ and the current $\left(i_{\mathrm{MS}}\right)$ of the MS were displayed in Figure $3 \mathrm{~b}, \mathrm{c}$, respectively.

The fault starting time is indicated with $t_{1}$ in Figure 3 . After $t_{1}$, the time for the current of the $\mathrm{SCE}_{1}\left(i_{\mathrm{SCE} 1}\right)$ to arrive at the critical current $\left(I_{\mathrm{C} 1}\right)$ is marked with $t_{\mathrm{C} 1}$. After that time, the voltage of the MS sharply increases and the arc starting time is notated with $t_{\mathrm{Arc}}$ as seen in Figure $3 \mathrm{~b}$. As $t_{\mathrm{Arc}}$, the current of the MS ( $i_{\mathrm{MS}}$ ) as seen in Figure $3 \mathrm{c}$ increases with the parabola form together with the resonance due to the LC series resonance circuit. Though the increase of the MS's current, the current in the $\mathrm{SCE}_{1}\left(i_{\mathrm{SCE} 1}\right)$ due to its quench occurrence decreases, which makes the current in the $\mathrm{SCE}_{2}\left(i_{\mathrm{SCE}}\right)$ or the $\mathrm{CLR}_{1}\left(i_{\mathrm{CLR} 1}\right)$ increase on the other way. The increased current of the $\mathrm{SCE}_{2}$ is observed to approach its critical current $\left(I_{\mathrm{C} 2}\right)$ at $t_{\mathrm{C} 2}$. The decrease of the $\mathrm{SCE}_{2^{\prime}} \mathrm{s}$ current due to its quench occurrence again causes the current of the $\mathrm{CLR}_{2}$ to be increased as seen in Figure 3a. Through twice or double quench occurrence in two SCEs and the series resonance, the current of the MS ( $\left.i_{\mathrm{MS}}\right)$ smoothly increases with the series resonance frequency due to the series LC circuit and then, approaches the zero current point at $t_{S A}$. On the other hand, the voltage of the DCCB $\left(v_{\mathrm{DCCB}}\right)$ sharply starts to increase at the moment of the zero current point and exceeds the breaking voltage $\left(V_{\mathrm{B}}\right)$ as seen in Figure $3 \mathrm{~b}$. However, the operation of the surge arrestor, as seen in the current occurrence of the surge 
arrestor $\left(i_{S A}\right)$ from Figure $3 a$, is confirmed to be contributed to suppressing the overvoltage of the DCCB.
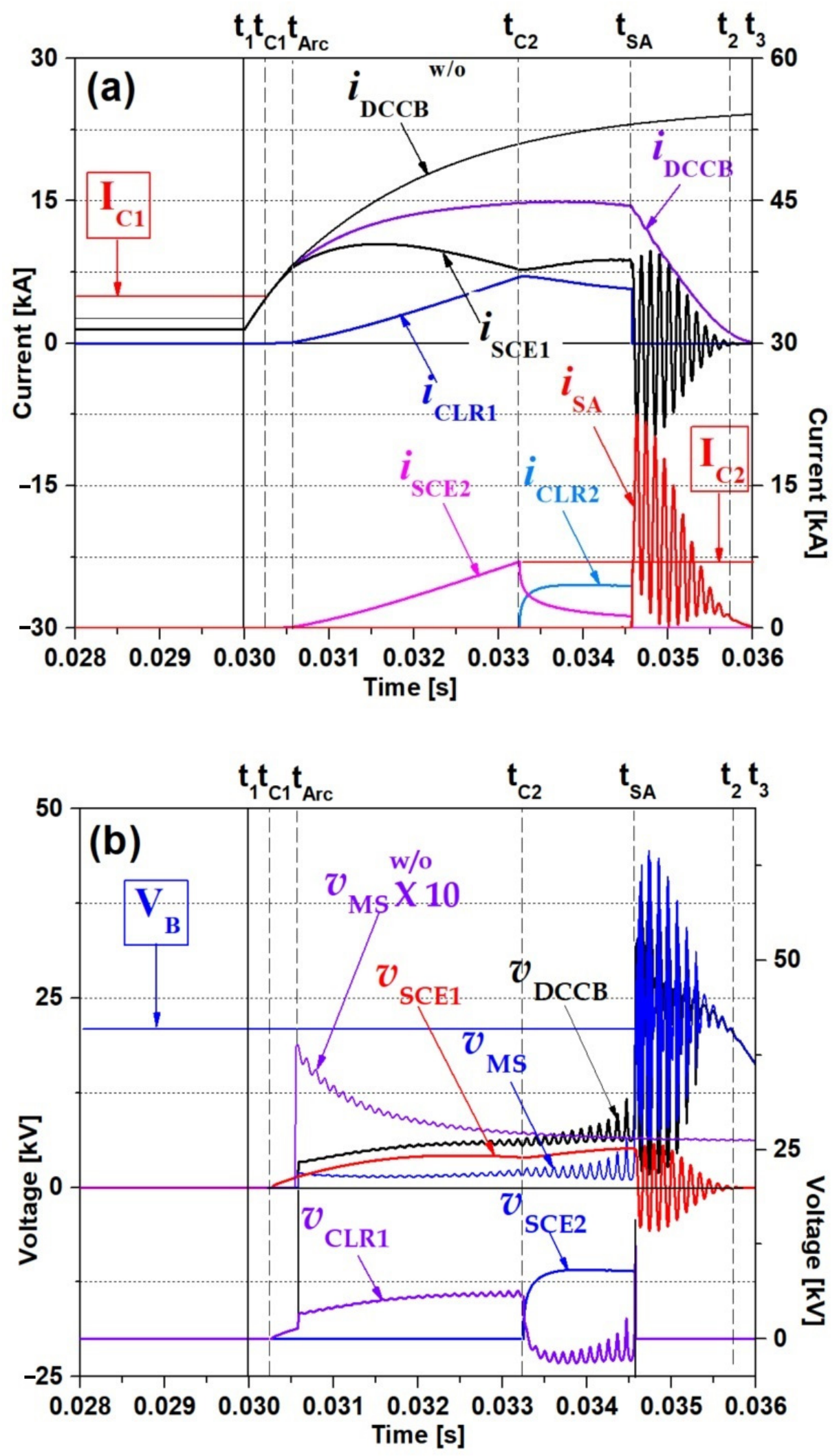

Figure 3. Cont. 


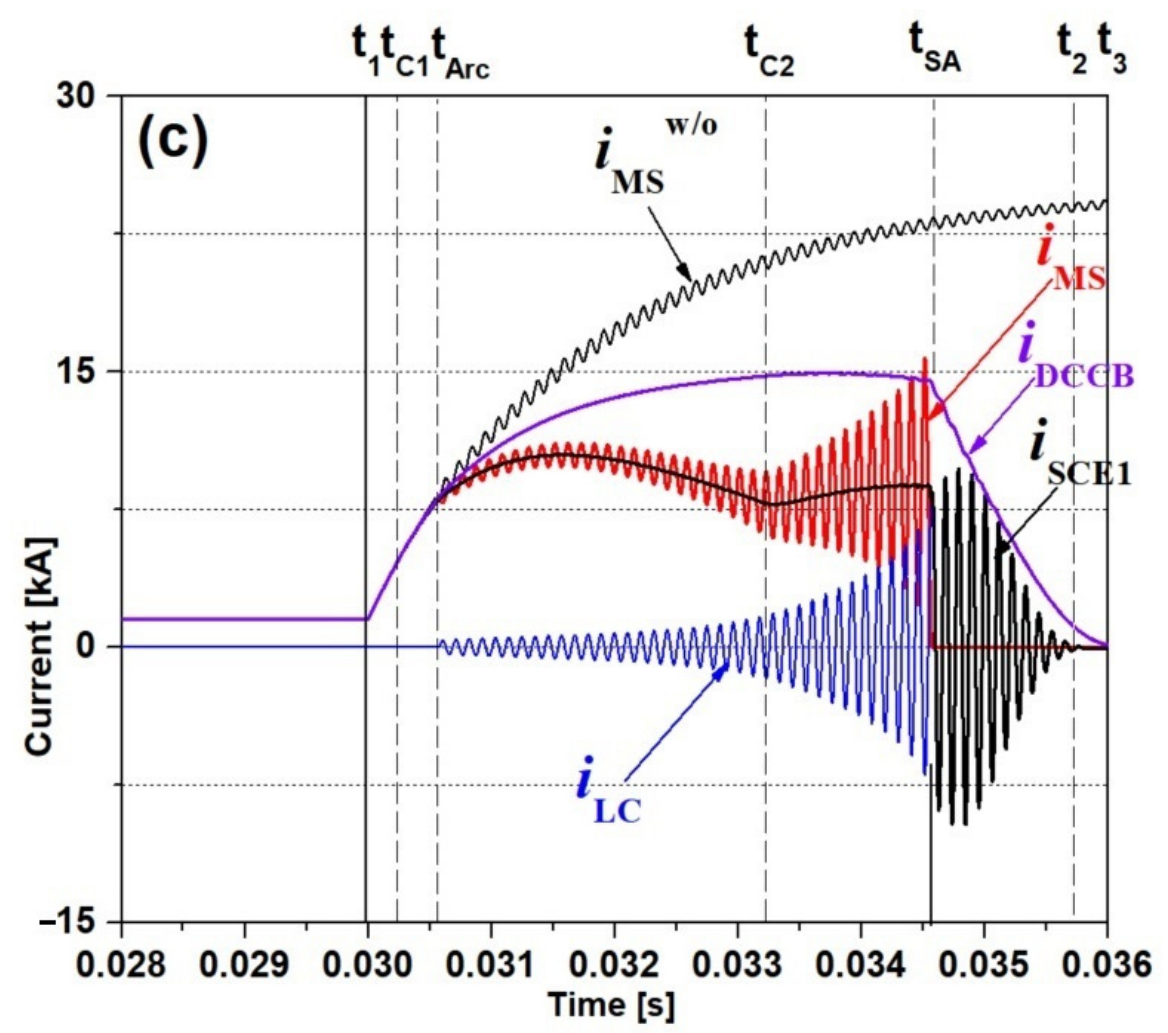

Figure 3. DC fault current limiting and interrupting operation waveforms of the hybrid DCCB using double quench in case of the larger DC fault current occurrence. (a) Current waveforms of $\mathrm{DCCB}, \mathrm{SCE}_{1}, \mathrm{SCE}_{2}, \mathrm{CLR}_{1}, \mathrm{CLR}_{2}$ and $\mathrm{SA}\left(i_{\mathrm{DCCB}}, i_{\mathrm{SCE} 1}, i_{\mathrm{SCE} 2}, i_{\mathrm{CLR} 1}, i_{\mathrm{CLR} 2}, i_{\mathrm{SA}}\right)$. (b) Voltage waveforms of DCCB, MS, $\mathrm{SCE}_{1}, \mathrm{SCE}_{2}, \mathrm{CLR}_{1}\left(v_{\mathrm{DCCB}}, v_{\mathrm{MS}}, v_{\mathrm{SCE} 1}, v_{\mathrm{SCE} 2}, v_{\mathrm{CLR} 1}\right)$. (c) DC current limiting and interrupting waveforms of DCCB, MS, LC, $\mathrm{SCE}_{1}\left(i_{\mathrm{DCCB}}, i_{\mathrm{MS}}, i_{\mathrm{LC}}, i_{\mathrm{SCE} 1}\right)$.

After the MS opens, the current of the $\mathrm{SCM}_{1}$ (i $i_{\mathrm{SCE} 1}$ ) starts to decrease with the amplitude of the resonance frequency due to the series LC resonance circuit and then, finally approaches to zero value at $t_{2}$. In the end, the current of DCCB of the hybrid DCCB reaches zero value at $t_{3}$ as seen in Figure 3 a.

For the comparative analysis with the hybrid DCCB without the SCMs and the CLRs, the currents of the DCCB and the MS $\left(i_{\mathrm{DCCB}}{ }^{w / o}, i_{\mathrm{MS}}{ }^{w / o}\right)$ and the voltage of the MS $\left(v_{\mathrm{MS}}{ }^{w / o}\right)$ were included in Figure 3. As seen in Figure 3, the MS in the case of the hybrid DCCB without the SCMs and the CLRs can be seen to be not open or fail to be open.

In the case of the lower DC fault current occurrence, which was simulated by closing $\mathrm{SW}_{22}$ after $\mathrm{SW}_{1}$ was closed as shown in Figure 2, the DC fault current limiting and interrupting operations of the suggested hybrid DCCB were displayed in Figure 4. Both the time $\left(t_{\mathrm{C} 1}\right)$ for the current of the $\mathrm{SCE}_{1}\left(i_{\mathrm{SCE} 1}\right)$ to arrive at the critical current $\left(I_{\mathrm{C} 1}\right)$ and the time $\left(t_{\mathrm{Arc}}\right)$ for the voltage of the MS ( $\left.v_{\mathrm{MS}}\right)$ rapidly to start to increase is seen to be a little longer compared to the larger DC fault current occurrence as analyzed in Figure 3. Furthermore, the second fault current limiting operation did not happen since the current of the $\mathrm{SCE}_{2}\left(i_{\mathrm{SCE} 2}\right)$ did not exceed its critical current $\left(I_{\mathrm{C} 2}\right)$ as seen in Figure $4 \mathrm{a}$. After $t_{\mathrm{Arc}}$ the current in the MS ( $\left.i_{\mathrm{MC}}\right)$, which kept zero value before $t_{\mathrm{Arc}}$, starts to increase with the resonance frequency of series LC circuit and then, approaches zero point at $t_{\mathrm{SA}}$ by the increase of the current $\left(i_{\mathrm{LC}}\right)$ in series LC circuit as seen in Figure $4 \mathrm{c}$. 
Simultaneously, as soon as the current of the MS approaches zero point at $t_{\mathrm{SA}}$, the voltage of the MS $\left(v_{\mathrm{MS}}\right)$, as shown in Figure $4 \mathrm{~b}$, exceeds the breaking voltage $\left(V_{\mathrm{B}}\right)$, and then, the current of the surge arrestor $\left(i_{\mathrm{SA}}\right)$ starts to flow as displayed in Figure $4 \mathrm{a}$.

After $t_{\mathrm{SA}}$, the zero current time of the $\mathrm{SCM}_{1}\left(t_{2}\right)$ and the zero current time of the DCCB $\left(t_{3}\right)$ were accompanied. This time $t_{3}$ was called the complete opening time.

Due to the lower DC fault current, the voltage and current levels in components comprising the hybrid DCCB as analyzed in Figure 4 were observed to have a small scale compared to the larger DC fault current. Therefore, the complete opening time $\left(t_{3}\right)$ in the case of the lower DC fault current occurrence seems to be shorter than the case of the larger DC fault current. To compare the hybrid DCCB without two SCMs and two separated CLRs, the DC fault current limiting and interrupting waveforms of the suggested hybrid DCCB were displayed in Figure 5 together. In the case of the larger DC fault current occurrence, as shown in Figure $5 a$, the complete opening operation at $t_{3}$ after the zero current in the MS through the series resonance of LC together with the twice DC fault current limiting operations of two SCMs was achieved. On the other hand, the DC fault current interrupting operation $\left(i_{\mathrm{MS}}{ }^{w / 0}, i_{\mathrm{DCCB}}{ }^{w / 0}\right)$ in the case of the hybrid DCCB without two SCMs and two CLRs was not achieved.

To compare the hybrid DCCB without two SCMs and two separated CLRs, the DC fault current limiting and interrupting waveforms of the suggested hybrid DCCB were displayed in Figure 5 together. In the case of the larger DC fault current occurrence, as shown in Figure $5 \mathrm{a}$, the complete opening operation at $t_{3}$ after the zero current in the MS through the series resonance of LC together with the twice DC fault current limiting operations of two SCMs was achieved. On the other hand, the DC fault current interrupting operation $\left(i_{\mathrm{MS}}{ }^{w / o}, i_{\mathrm{DCCB}}{ }^{w / o}\right)$ in case the hybrid DCCB without two SCMs and two CLRs was not achieved.

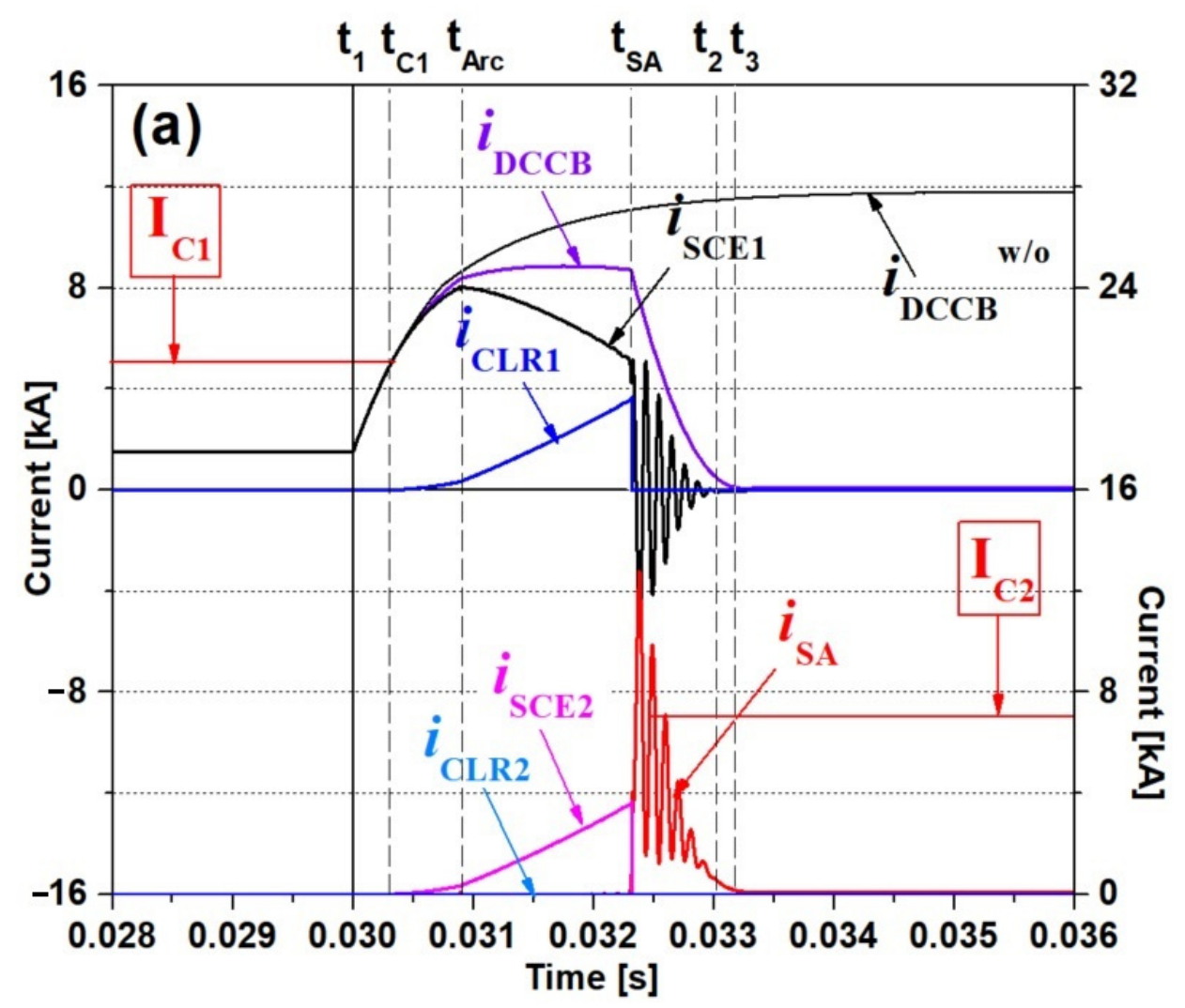

Figure 4. Cont. 

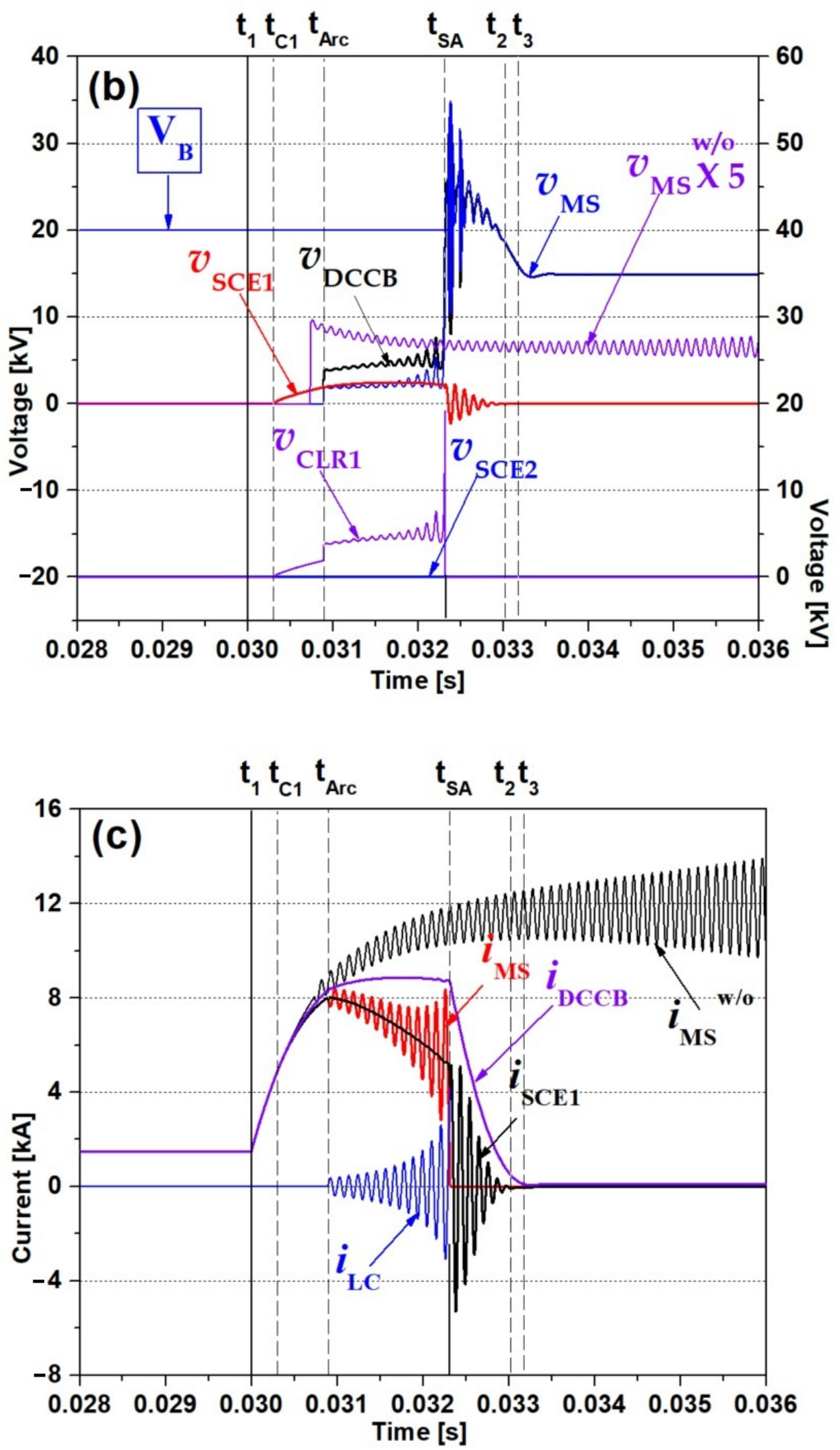

Figure 4. DC fault current limiting and interrupting operation waveforms of the hybrid DCCB using double quench in case of the lower DC fault current occurrence. (a) Current waveforms of $\mathrm{DCCB}, \mathrm{SCE}_{1} \mathrm{SCE}_{2}, \mathrm{CLR}_{1}, \mathrm{CLR}_{2}$ and $\mathrm{SA}\left(i_{\mathrm{DCCB}}, i_{\mathrm{SCE} 1}, i_{\mathrm{SCE} 2}, i_{\mathrm{CLR} 1}, i_{\mathrm{CLR} 2}, i_{\mathrm{SA}}\right)$. (b) Voltage waveforms of DCCB, MS, $\mathrm{SCE}_{1}, \mathrm{SCE}_{2}, \mathrm{CLR}_{1}\left(v_{\mathrm{DCCB}}, v_{\mathrm{MS}}, v_{\mathrm{SCE} 1}, v_{\mathrm{SCE} 2}, v_{\mathrm{CLR} 1}\right)$. (c) DC current limiting and interrupting waveforms of DCCB, MS, LC, $\mathrm{SCE}_{1}\left(i_{\mathrm{DCCB}}, i_{\mathrm{MS}}, i_{\mathrm{LC}}, i_{\mathrm{SCE} 1}\right)$. 

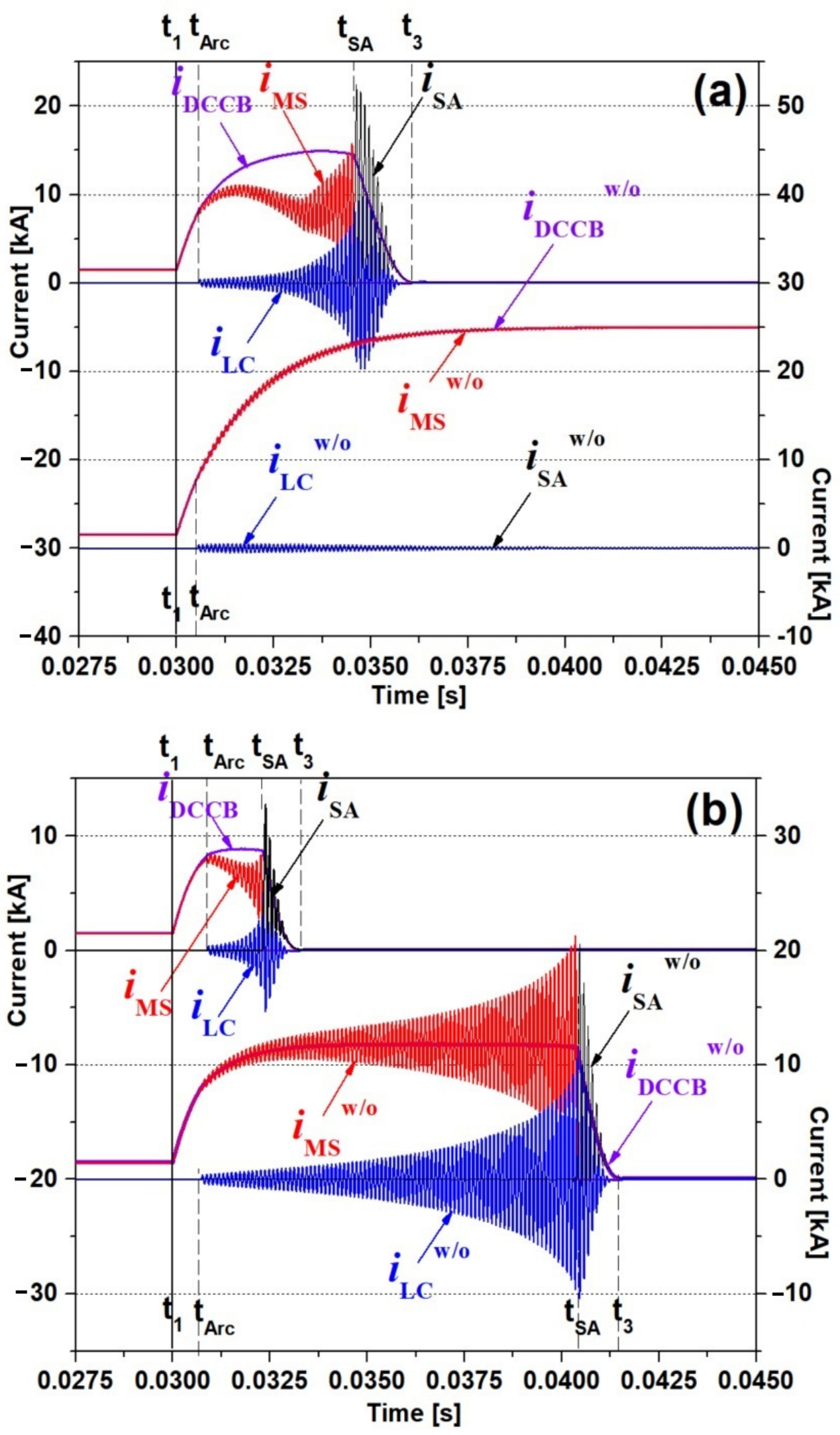

Figure 5. Comparative waveforms of DC fault current limiting and interrupting operation of the hybrid DCCB using double quench for the case without the hybrid DCCB. (a) In case of the larger DC fault current occurrence, (b) In case of the lower DC fault current occurrence. 
Unlike the case of the larger DC fault current occurrence, the DC fault current interrupting operation $\left(i_{\mathrm{MS}}{ }^{w / o}, i_{\mathrm{DCCB}}{ }^{w / o}\right)$ without two SCMs and two CLRs in case of the lower DC fault current occurrence was observed to succeed as shown in Figure 5b, which was made to zero current by the series LC resonance. However, it is compared to take a longer time compared to the case of the hybrid DCCB using the double quench although the quench in only $\mathrm{SCE}_{1}$ comprising the hybrid DCCB using the double quench due to the lower DC fault current occurred.

\section{Conclusions}

In this paper, the hybrid DC circuit breaker using double quench was suggested and its DC fault current limiting and interrupting operation according to DC fault current amplitude was analyzed through the PSCAD/EMTDC modeling for its components. In the case of the larger DC fault current occurrence, the DC fault current interrupting operation through zero current generation in the MS using the series resonance together with the twice DC fault current limiting operations of two SCMs was successively achieved. On the other hand, the DC fault current interrupting operation in case with the hybrid DCCB without two SCMs and two CLRs was not achieved. In case of lower DC fault current occurrence, the DC fault current interrupting operation of the suggested hybrid DCCB was also made through once DC fault current limiting operation. However, the opening time was shorter than the case of the larger DC fault current.

In the future, the studies considering the application of the suggested hybrid DCCB into the multi-terminal MVDC system, which requires several DCCBs with different capacities, will be in progress.

Author Contributions: Writing—original draft, S.-H.L.; Writing—review and editing, S.-J.C.; Formal analysis, J.-H.L.; Investigation, J.-W.L. All authors have read and agreed to the published version of the manuscript.

Funding: This work was supported by the Soongsil University Research Fund (Convergence Research) of 2020 and was also supported by the National Research Foundation of Korea (NRF) grant funded by the Korean government (MOE) (No. 2020R1F1A1077206).

Institutional Review Board Statement: Not applicable.

Informed Consent Statement: Not applicable.

Data Availability Statement: Data is contained within the article.

Conflicts of Interest: The authors declare no conflict of interest.

\section{References}

1. Nakao, H.; Nakagoshi, Y.; Hatano, M.; Koshizuka, T.; Nishiwaki, S.; Kobayashi, A.; Murao, T.; Yanabu, S. DC Current Interruption in HVDC SF6 Gas MRTB by Means of Self-Excitation. IEEE Power Eng. Rev. 2001, 21, 62. [CrossRef]

2. Callavik, M.; Blomberg, A.; Häfner, J.; Jacobson, B. Hybrid HVDC Breaker. ABB Grid Syst. Tech. Pap. 2012, 361, $143-152$.

3. Sneath, J.; Rajapakse, A.D. Fault Detection and Interruption in an Earthed HVDC Grid Using ROCOV and Hybrid DC Breakers. IEEE Trans. Power Deliv. 2016, 31, 973-981. [CrossRef]

4. Meyer, C.; Kowal, M.; de Doncker, R.W. Circuit breaker concepts for future high-power DC-applications. In Conference Record of the 2005 Industry Applications Conference, Proceedings of the Fourtieth IAS Annual Meeting, Kowloon, Hong Kong, 2-6 October 2005; Institute of Electrical and Electronics Engineers: Piscataway, NJ, USA, 2005. [CrossRef]

5. Thomas, D.W.P.; Pereira, E.T.; Christopoulos, C.; Howe, A.F. The simulation of circuit breaker switching using a composite Cassie-modified Mayr model. IEEE Trans. Power Deliv. 1955, 10, 1829-1835. [CrossRef]

6. Lee, J.; Khan, U.A.; Lee, H.; Lee, B. Impact of SFCL on the Four Types of HVDC Circuit Breakers by Simulation. IEEE Trans. Appl. Supercond. 2016, 26, 1-6.

7. Xiang, B.; Tan, Y.; Yang, K.; Liu, Z.; Geng, Y.; Wang, J.; Yanabu, S. Quenched Resistance Effects on a Superconducting CurrentLimiting-Type DC Breaker. IEEE Trans. Appl. Supercond. 2016, 26, 1-5. [CrossRef]

8. Zhoua, G.; Hana, M.; Filizadehb, S.; Caoa, X.; Huang, W. Studies on the combination of RSFCLs and DCCBs in MMC-MTDC system protection. Int. J. Electr. Power Energy Syst. 2021, 125, 106532. [CrossRef]

9. Liang, S.; Tang, Y.; Ren, L.; Xu, Y.; Shi, J.; Li, Z.; Tan, X. Parameter Matching and Optimization of a Hybrid Type DC SFCL Considering the Transient Characteristics of VSC-Based DC Systems. Energies 2019, 12, 3522. [CrossRef] 
10. Lee, H.; Asif, M.; Park, K.; Lee, B. Feasible protection strategy for HVDC system by means of SFCL and passive resonance DC breaker. IET J. Eng. 2019, 2019, 767-770. [CrossRef]

11. van der Sluis, L. Transients in Power Systems; John Wiley \& Sons: Hoboken, NJ, USA, 2001.

12. Walter, M.M. Switching Arcs in Passive Resonance HVDC Circuit Breakers. Ph.D. Thesis, ETH Zürich, Zürich, Switzerland, 2013

13. Yamaguchi, H.; Kataoka, T. Current Limiting Characteristics of Transformer Type Superconducting Fault Current Limiter with Shunt Impedance and Inductive Load. IEEE Trans. Appl. Supercond. 2008, 18, 668-671. [CrossRef]

14. Babaei, M.; Abdelwahed, S.; Kluss, J.V.; Jafari-Marandi, R. A novel approach for optimal design of superconducting fault current limiter. In Proceedings of the 2018 IEEE Texas Power and Energy Conference (TPEC), College Station, TX, USA, 12 March 2018.

15. Žitnik, B.; Babuder, M.; Muhr, M.; Žitnik, M.; Thottappillil, R. Numerical Modelling of Metal Oxide Varistors. In Proceedings of the XIVth International Symposium on High Voltage Engineering, Beijing, China, 25-29 August 2005. 